\title{
Performance Evaluation of Stochastic Model of a Paper Machine Having Three Types of Faults
}

\author{
Veena Rani \\ Research Scholar \\ Dept.of Mathematics \\ Baba Mastnath University \\ Rohtak,Haryana,India
}

Pooja Bhatia

Associate Professor

Dept. of Mathematics,

Baba Mastnath University

Rohtak, Haryana,India

\begin{abstract}
Aim of present paper is to evaluate the performance of a paper machine installed in a paper mill of Northern Haryana namely Sri Jagdumbe Paper Mills Ltd. located at Sirsa (Haryana) using stochastic modeling of a single unit considering three types of faults i.e. minor, major faults and power failure during operation of the machine. Minor/major faults are repairable as well as non repairable and for the purpose of calculations in this paper, it is assumed that there is facility of single repairman for inspection, repair and replacement etc. Considering all these aspects and using the real data collected from the mill, various measures of system effectiveness such as MTSF, Reliability, Availability and Busy period etc. are derived by using Semi-Markov process and Regenerative Point technique. The performance of the machine is evaluated using numerical results and graphs derived thereof. From the graphs so obtained, we get cut-off points of profit for different values of rates of minor, major faults/ revenue of availability/ costs etc., which will helpful for management team of Paper Mill to make the paper machine more yielding.
\end{abstract}

Keywords: availability; MTSF; performance; reliability; Regenerative Point technique. 
International Journal of Science and Engineering Applications

Volume 9 - Issue 07, 91 - 102, 2020, ISSN:- 2319 - 7560

\section{INTRODUCTION:}

Paper has several uses in different form in almost all the fields, therefore, paper industry has its own importance and it plays a vital role in the economic as well as social growth of a country. In the present scenario of competitive market, improvement in performance of the machines with minimum operating cost is the main objective of each industry. In the present paper, real data relating to a paper machine, installed in Sri Jagdumbe Paper Mlls Ltd. Sirsa, has been collected personally by visiting the said mill premises from time to time and a stochastic model is developed considering its various types of faults using Semi-Markov Process and Regenerative Point Technique. The paper machine is a single unit complex system with various sub systems wherein different faults occur during operation. The faults are categorised as minor and major faults on the basis of down time and cost which are repairable as well as non-repairable. Since the machine is operative round the clock, therefore, power failures/ degradation are also considered as faults. It is observed that on occurrence of a minor fault, machine partially stopped and we get the product with reduced capacity, whereas in case of major fault, operation of the machine is completely stopped. Further, in case of power failures/ degradation, the machine stops temporarily i.e. for few minutes. There is a single repairman who visits the machine immediately whenever needed. Firstly, he inspects the machine for fault finding and observes whether the fault is repairable or non-repairable. In case of repairable fault, the defective part is repaired whereas in case of non-repairable fault, the defective part of the machine is replaced. For numerical calculations, inspection rates, repair rates and replacement rates are assumed to follow Exponential Distributions. On the basis of so collected real data, by using Semi-Markov Process and Regenerative Point Technique, various measures of system effectiveness such as MTSF, Reliability, Availability (with full and reduced capacity) and Busy Period of repairman are obtained. Finally, numerical calculations and graphs drawn on the basis thereof have been used for evaluation of performance of the machine which is useful for smooth and better functioning of the industry.
So many Researchers and Scientists are trying to improve the performance of industries using various reliability techniques. Branson and Shah (1971) discussed a system with exponential failure and arbitrary repair distributions while adopting Semi-Markov Process. Nakagawa (1976) considered the replacement of the unit at a certain level of damage whereas. Goel et al. (1986) obtained the reliability analysis of a system with preventive maintenance. Kumar et al. (1989) analysed the reliability and availability behaviour of subsystems of paper industry by using probabilistic approach. Gupta et al. (2005) worked on the system reliability and availability in butter oil processing plant by using Markov Process and R-K method. Kumar and Bhatia (2011) discussed reliability and cost analysis of a one unit centrifuge system with single repairman and Inspection. Malik et al.(2012) analysed a stochastic model of a repairable system of a non-identical units with priority for operation and repair subject to weather conditions. Bhatia and Kumar (2013) studied Performance and Profit Evaluations of a Stochastic Model on Centrifuge System Working in Thermal Power Plant Considering Neglected Faults. Sharma and Vishwakarma (2014) applied Markov Process in performance analysis of feeding system of sugar industry. Renu and Bhatia (2017) dealt with reliability analysis for removing shortcomings using stochastic processes and applied for maintenance in industries. A few of the Researchers have worked for real data of paper machine. Rajaprasad (2018) investigated the reliability, availability and maintainability (RAM) characteristics of a paper machine from a paper mill.

For the purpose of performance evaluation, a stochastic model is developed by using Regenerative Point Technique and following measures of system effectiveness are obtained:

- Transition Probabilities

- Mean Sojourn Time

- $\quad$ Mean Time to System Failure (MTSF)

- Reliability

- Availability with full/reduced capacity

- Busy Period of Service man (Inspection, Repair, Replacement time)

- $\quad$ Power Degradation Period

- Performance Analysis (Profit) 


\section{ASSUMPTIONS:}

- The system consists of a single unit,

- The system is as good as new after each repair and replacement.

- The Service man reaches the system in negligible time.

- A single Service man facility is provided to the system for inspection, repair and replacement of the components.

- Time distributions of various faults i.e. minor/major/ power failure are Exponential distribution and other time distributions are general.

- A minor fault leads to degradation/failure whereas a major fault leads to complete failure.

- Due to power failure/degradation the machine stops temporarily for few minutes.

\section{NOTATIONS:}

\begin{tabular}{|c|c|}
\hline O: & Operative Unit. \\
\hline$\lambda_{1} / \lambda_{2} / \lambda_{3}:$ & $\begin{array}{l}\text { Rate of minor faults/ major faults/ power } \\
\text { failure. }\end{array}$ \\
\hline $\mathbf{a} / \mathbf{b}:$ & $\begin{array}{l}\text { Probability that a minor fault to be } \\
\text { repairable/ non-repairable. }\end{array}$ \\
\hline $\mathbf{x} / \mathbf{y}:$ & $\begin{array}{l}\text { Probability that a major fault to be } \\
\text { repairable/ non- repairable. }\end{array}$ \\
\hline $\mathrm{i}_{1}(\mathrm{t}) / \mathrm{I}_{1}(\mathrm{t}):$ & $\begin{array}{l}\mathrm{pdf} / \mathrm{cdf} \text { of rate of inspection of a minor } \\
\text { fault w.r.t. time. }\end{array}$ \\
\hline $\mathrm{i}_{2}(\mathrm{t}) / \mathrm{I}_{2}(\mathrm{t}):$ & $\begin{array}{l}\mathrm{pdf} / \mathrm{cdf} \text { of rate of inspection of a major } \\
\text { fault w.r.t. time. }\end{array}$ \\
\hline $\mathrm{g}_{1}(\mathrm{t}) / \mathrm{G}_{1}(\mathrm{t}):$ & $\begin{array}{l}\mathrm{pdf} / \mathrm{cdf} \text { of repair rate of minor faults w.r.t. } \\
\text { time. }\end{array}$ \\
\hline $\mathrm{g}_{2}(\mathrm{t}) / \mathrm{G}_{2}(\mathrm{t}):$ & $\begin{array}{l}\text { pdf/cdf of repair rate of major faults w.r.t. } \\
\text { time. }\end{array}$ \\
\hline $\mathrm{h}_{1}(\mathrm{t}) / \mathrm{H}_{1}(\mathrm{t}):$ & $\begin{array}{l}\text { pdf/cdf of replacement rate of minor faults } \\
\text { w.r.t. time. }\end{array}$ \\
\hline $\mathrm{h}_{2}(\mathrm{t}) / \mathrm{H}_{2}(\mathrm{t}):$ & $\begin{array}{l}\text { pdf/cdf of replacement rate of major faults } \\
\text { w.r.t. time. }\end{array}$ \\
\hline
\end{tabular}

$\mathrm{k}_{1}(\mathrm{t}) / \mathrm{K}_{1}(\mathrm{t})$ : $\quad$ pdf/cdf of rate of power degradation/ failure w.r.t. time.

()/(5: Laplace convolution/ Laplace stieltjes convolution.

*/**: $\quad$ Laplace transformation/ Laplace stieltjes transformation.

$\mathrm{q}_{\mathrm{ij}}(\mathrm{t}) / \mathrm{Q}_{\mathrm{ij}}(\mathrm{t})$ : $\quad$ pdf/cdf for the transition of the system from one regenerative state $S_{i}$ to another regenerative state $S_{j}$ or to a failed state $S_{j}$.

\section{MODEL DESCRIPTION:}

Different states of the system model according to Semi Markov process and Regenerative Point Technique are as follows:

State 0: Initial operative state.

State 1: Operative unit partially failed due to some minor faults.

State 2: Unit completely failed due to some major faults.

State 3: Unit temporarily failed due to power degradation/ failure.

State 4: After inspection unit undergoes for repair of minor fault and system is operative.

State 5: After inspection unit undergoes for removal of minor fault by replacement of components/ parts and system is operative.

State 6: After inspection unit undergoes for repair of major fault and system is operative.

State 7: After inspection unit undergoes for removal of major fault by replacement of components/ parts and system is operative.

Here, state 0 is operative state with full capacity whereas 1,4 and 5 are operative states with reduced capacity, state 3 is temporarily failed and states 2,6 and 7 are failed states. 


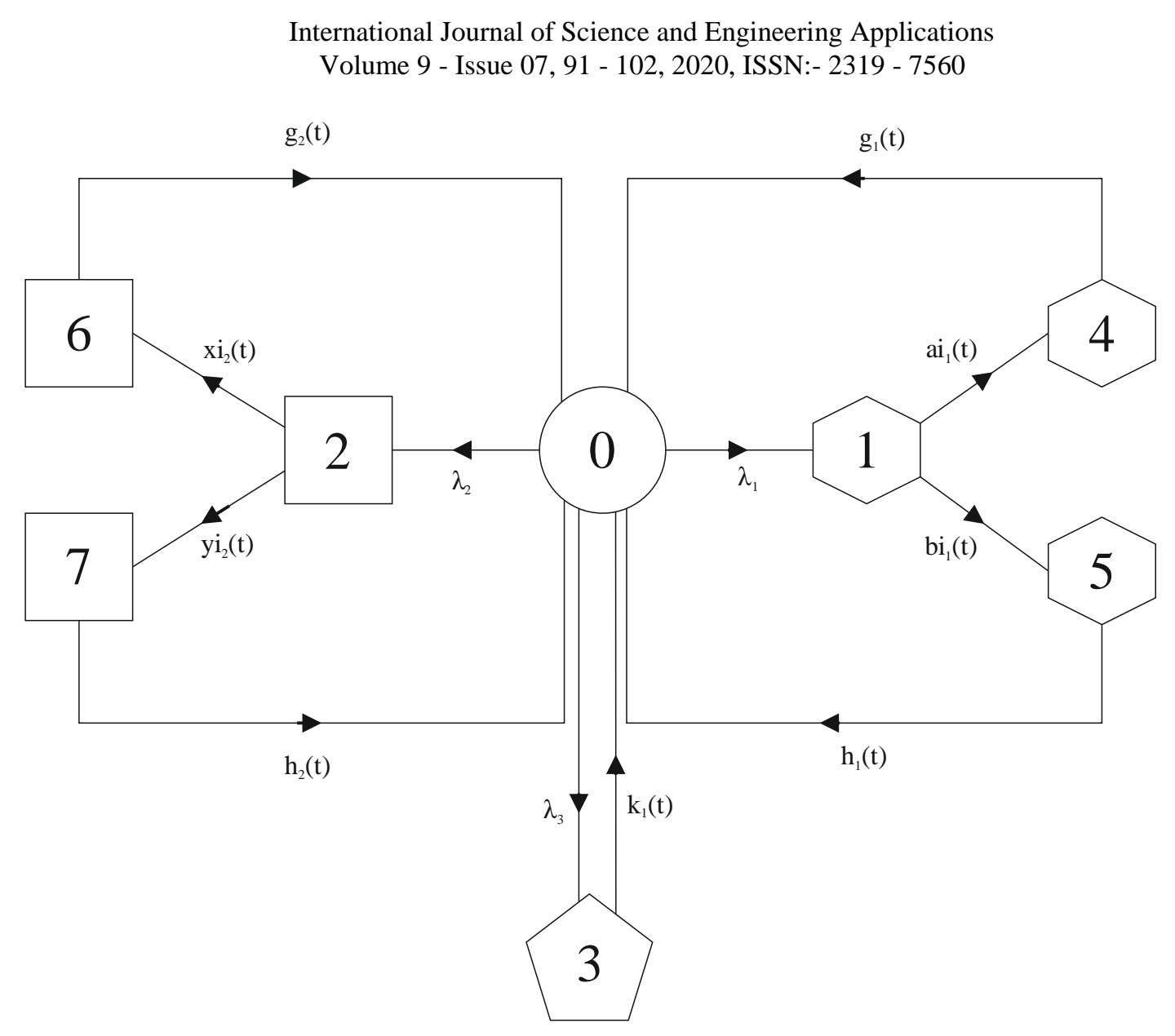

Figure.1. Model

$\bigcirc$ Operative State $\square$ Failed State $\bigcirc$ Degraded State $\bigcirc$ Temporary/short Failed State

\section{RELIABILITY INDICATORS:}

\subsection{Transition Probabilities:}

By simple probabilistic arguments, we can find transition probabilities given by:

$$
\begin{array}{ll}
\mathrm{p}_{\mathrm{ij}}=\lim _{\mathrm{s} \rightarrow 0} \mathrm{Q}_{\mathrm{ij}}^{* *}(\mathrm{~s}) & \text { where, } \\
\mathrm{p}_{01}=\frac{\lambda_{1}}{\lambda_{1}+\lambda_{2}+\lambda_{3}} & \mathrm{p}_{02}=\frac{\lambda_{2}}{\lambda_{1}+\lambda_{2}+\lambda_{3}} \\
\mathrm{p}_{03}=\frac{\lambda_{3}}{\lambda_{1}+\lambda_{2}+\lambda_{3}} & \mathrm{p}_{14}=\mathbf{a} \mathrm{i}_{1}^{*}(0)=\mathbf{a} \\
\mathrm{p}_{15}=\mathrm{bi}_{1}^{*}(0)=\mathbf{s t} \mathrm{Q}_{\mathrm{ij}}(\mathrm{t}) \mathrm{dt} \\
\mathrm{p}_{27}=\mathrm{yi}_{2}^{*}(0)=\mathbf{y} & \mathrm{p}_{26}=\mathrm{xi}_{2}^{*}(0)=\mathbf{x} \\
& \mathrm{p}_{30}=\mathrm{k}_{1}^{*}(0)=1
\end{array}
$$

$$
\begin{array}{ll}
\mathrm{p}_{40}=\mathrm{g}_{1}^{*}(0)=1 & \mathrm{p}_{50}=\mathrm{h}_{1}^{*}(0)=1 \\
\mathrm{p}_{60}=\mathrm{g}_{2}^{*}(0)=1 & \mathrm{p}_{70}=\mathrm{h}_{2}^{*}(0)=1
\end{array}
$$

It is simple to verify that

$$
\begin{aligned}
& \mathrm{p}_{01}+\mathrm{p}_{02}+\mathrm{p}_{03}=1, \mathrm{p}_{14}+\mathrm{p}_{15}=\mathbf{a}+\mathbf{b}=1, \\
& \mathrm{p}_{26}+\mathrm{p}_{27}=\mathbf{x}+\mathbf{y}=1, \mathrm{p}_{30}=\mathrm{p}_{40}=\mathrm{p}_{50}=\mathrm{p}_{60}=\mathrm{p}_{70}=1
\end{aligned}
$$

\subsection{Means Sojourn Time:}

The unconditional mean time taken by the system to transit from any regenerative state $S_{i}$ into state $S_{j}$ when time is counted from epoch of entrance is given by:

$$
\mathrm{m}_{\mathrm{ij}}=\int_{0}^{\infty} \mathrm{tdQ}_{\mathrm{ij}}(\mathrm{t})=-\mathrm{Q}_{\mathrm{ij}}^{* \prime}(0)
$$


Thus, $\mathrm{m}_{01}=\frac{\lambda_{1}}{\left(\lambda_{1}+\lambda_{2}+\lambda_{3}\right)^{2}} \quad \mathrm{~m}_{02}=\frac{\lambda_{2}}{\left(\lambda_{1}+\lambda_{2}+\lambda_{3}\right)^{2}}$

$\mathrm{m}_{03}=\frac{\lambda_{3}}{\left(\lambda_{1}+\lambda_{2}+\lambda_{3}\right)^{2}}$

$\mathrm{m}_{14}=-\mathbf{a} \mathrm{i}_{1}^{{ }^{\prime \prime}}(0) \quad \mathrm{m}_{15}=-\mathbf{b}_{1}^{* \prime}(0) \quad \mathrm{m}_{26}=-\mathrm{xi}_{2}^{*{ }^{* \prime}}(0)$

$\mathrm{m}_{27}=-\mathrm{yi}_{2}^{* \prime}(0) \quad \mathrm{m}_{30}=-\mathrm{k}_{1}^{* \prime}(0) \quad \mathrm{m}_{40}=-\mathrm{g}_{1}^{* \prime}(0)$

$\mathrm{m}_{50}=-\mathrm{h}_{1}^{* \prime}(0) \quad \mathrm{m}_{60}=-\mathrm{g}_{2}^{* \prime}(0) \quad \mathrm{m}_{70}=-\mathrm{h}_{2}^{* \prime}(0)$

Also, Mean Sojourn Time in state $S_{i}$ is given by:

$\mu_{\mathrm{i}}=\int_{0}^{\infty} P(T>t) \mathrm{dt}$

$\mu_{0}=\frac{1}{\lambda_{1}+\lambda_{2}+\lambda_{3}} \quad \mu_{1}=-i_{1}^{* \prime}(0) \quad \mu_{2}=-i_{2}^{* \prime \prime}(0)$

$\mu_{3}=-\mathrm{k}_{1}^{* \prime}(0) \quad \mu_{4}=-\mathrm{g}_{1}^{* \prime}(0) \quad \mu_{5}=-\mathrm{h}_{1}^{* \prime}(0)$

$\mu_{6}=-g_{2}^{* \prime}(0) \quad \mu_{7}=-h_{2}^{* \prime}(0)$

Thus, we see that

$m_{01}+m_{02}+m_{03}=\mu_{0}, \quad m_{14}+m_{15}=\mu_{1}, \quad m_{26}+m_{27}=\mu_{2}$

$\mathrm{m}_{30}=\mu_{3}, \mathrm{~m}_{40}=\mu_{4}, \quad \mathrm{~m}_{50}=\mu_{5}, \quad \mathrm{~m}_{60}=\mu_{6}, \mathrm{~m}_{70}=\mu_{7}$

\subsection{Measures of System Effectiveness:}

Using probabilistic arguments for regenerative processes, various recursive relations are obtained and are solved to find different measures of system effectiveness, which are as follows:

Mean time to system failure $(\mathrm{MTSF})=\frac{\mathrm{N}_{1}}{\mathrm{D}_{1}}$,

Where, $\mathrm{N}_{1}=\mu_{0}+\mu_{1} \mathrm{p}_{01}+\mu_{4} \mathrm{p}_{14} \mathrm{p}_{01}+\mu_{5} \mathrm{p}_{15} \mathrm{p}_{01}$

and $\mathrm{D}_{1}=\mathrm{p}_{02}+\mathrm{p}_{03}$

Availability per unit time with full capacity $\left(A_{0}\right)=\frac{N_{2}}{D_{2}}$,

Availability per unit time with reduced capacity $\left(\mathrm{RA}_{0}\right)=\frac{\mathrm{N}_{3}}{\mathrm{D}_{2}}$,

Busy period of service man (inspection time) $B_{0}^{I}=\frac{N_{4}}{D_{2}}$,
Busy period of service man (repair time) $\left(B_{0}^{R}\right)=\frac{N_{5}}{D_{2}}$,

Busy period of service man (replacement time) $\left(\mathrm{B}_{0}^{\mathrm{Rp}}\right)=\frac{\mathrm{N}_{6}}{\mathrm{D}_{2}}$,

Expected Power Degradation Period due to power failure/degradation $\left(D_{0}\right)=\frac{N_{7}}{D_{2}}$,

Where,

$\mathrm{N}_{2}=\mu_{0} ; \quad \mathrm{N}_{3}=\mu_{1} \mathrm{p}_{01}+\mu_{4} \mathrm{p}_{14} \mathrm{p}_{01}+\mu_{5} \mathrm{p}_{15} \mathrm{p}_{01} ; \mathrm{N}_{4}=\mu_{1} \mathrm{p}_{01}+\mu_{2} \mathrm{p}_{02} ;$

$\mathrm{N}_{5}=\mu_{4} \mathrm{p}_{01} \mathrm{p}_{14}+\mu_{6} \mathrm{p}_{02} \mathrm{p}_{26} ; \mathrm{N}_{6}=\mu_{5} \mathrm{p}_{01} \mathrm{p}_{15}+\mu_{7} \mathrm{p}_{02} \mathrm{p}_{27} ; \mathrm{N}_{7}=\mu_{3} \mathrm{p}_{03}$ and

$D_{2}=\mu_{0}+\mu_{1} p_{01}+\mu_{2} p_{02}+\mu_{3} p_{03}+\mu_{4} p_{14} p_{01}+\mu_{5} p_{15} p_{01}+\mu_{6} p_{02} p_{26}$ $+\mu>\mathrm{p}_{27} \mathrm{p}_{02}$

\subsection{Performance (Profit) Analysis:}

The performance of the system in the form of profit $\left(\mathrm{P}_{0}\right)$ can be figured as follows:

$\mathrm{P}_{0}=\mathrm{C}_{0} \mathrm{~A}_{0}+\mathrm{C}_{1} \mathrm{RA}_{0}-\mathrm{C}_{2} \mathrm{~B}_{0}^{\mathrm{I}}-\mathrm{C}_{3} \mathrm{~B}_{0}^{\mathrm{R}}-\mathrm{C}_{4} \mathrm{~B}_{0}^{\mathrm{Rp}}-\mathrm{C}_{5} \mathrm{D}_{0}-\mathrm{C}_{6}$

Where,

$\mathrm{C}_{0}=$ Revenue per unit availability with full capacity of the system;

$\mathrm{C}_{1}=$ Revenue per unit availability with reduced capacity of the system;

$\mathrm{C}_{2}=$ Cost per unit time of inspection;

$\mathrm{C}_{3}=$ Cost per unit time of repair;

$\mathrm{C}_{4}=$ Cost per unit time of replacement;

$\mathrm{C}_{5}=$ Cost per unit time of power degradation;

$\mathrm{C}_{6}=$ Miscellaneous cost.

\subsection{Numerical Study and Graphical Analysis:}

Giving some particular values to the parameters and considering

$\mathrm{k}_{1}(\mathrm{t})=\alpha_{1} \mathrm{e}^{-\alpha_{1}(\mathrm{t})}, \mathrm{h}_{1}(\mathrm{t})=\gamma_{1} \mathrm{e}^{-\gamma_{1}(\mathrm{t})}, \mathrm{h}_{2}(\mathrm{t})=\gamma_{2} \mathrm{e}^{-\gamma_{2}(\mathrm{t})}$,

$\mathrm{g}_{1}(\mathrm{t})=\beta_{1} \mathrm{e}^{-\beta_{1}(\mathrm{t})}, \mathrm{i}_{1}(\mathrm{t})=\eta_{1} \mathrm{e}^{-\eta_{1}(\mathrm{t})}, \mathrm{g}_{2}(\mathrm{t})=\beta_{2} \mathrm{e}^{\left.-\beta_{2} \mathrm{t}\right)}$,

$\mathrm{i}_{2}(\mathrm{t})=\eta_{2} \mathrm{e}^{-\eta_{2}(\mathrm{t})}$, 
International Journal of Science and Engineering Applications

Volume 9 - Issue 07, 91 - 102, 2020, ISSN:- 2319 - 7560

We get $\mathrm{p}_{01}=\frac{\lambda_{1}}{\lambda_{1}+\lambda_{2}+\lambda_{3}}, \quad \mathrm{p}_{02}=\frac{\lambda_{2}}{\lambda_{1}+\lambda_{2}+\lambda_{3}}$,

$\mathrm{p}_{03}=\frac{\lambda_{3}}{\lambda_{1}+\lambda_{2}+\lambda_{3}}, \mathrm{p}_{14}=\mathbf{a}, \mathrm{p}_{15}=\mathbf{b}$

$\mathrm{p}_{26}=\mathrm{x} \quad, \mathrm{p}_{27}=\mathrm{y}, \mathrm{p}_{30}=1, \mathrm{p}_{40}=1, \mathrm{p}_{50}=1, \mathrm{p}_{60}=1, \mathrm{p}_{70}=1 ;$

and $\mu_{0}=\frac{1}{\lambda_{1}+\lambda_{2}+\lambda_{3}}, \mu_{1}=\frac{1}{\eta_{1}}, \mu_{2}=\frac{1}{\eta_{2}}, \mu_{3}=\frac{1}{\alpha_{1}}$,

$\mu_{4}=\frac{1}{\beta_{1}}, \mu_{5}=\frac{1}{\gamma_{1}}, \mu_{6}=\frac{1}{\beta_{2}}, \mu_{7}=\frac{1}{\gamma_{2}}$.

For the above particular cases, taking values from the collected data and assuming the values

$\lambda_{1}=0.012, \lambda_{2}=0.007, \lambda_{3}=0.003, \alpha_{1}=4.5, \beta_{1}=4.71$,

$\beta_{2}=0.82, \gamma_{1}=3.25, \gamma_{2}=0.53, \eta_{1}=0.9, \quad \eta_{2}=0.7, \mathbf{a}=0.8, \quad \mathbf{b}$

$=0.2, \mathrm{x}=0.33, \mathrm{y}=0.67$.

We obtained the following values for the measures of system effectiveness:

Mean Time to System Failure (MTSF) $\left(\mathrm{T}_{0}\right)=101.357$
Availability per unit time with full capacity $\left(\mathrm{A}_{0}\right)=0.9635$

Availability per unit time with reduced capacity $\left(\mathrm{RA}_{0}\right)=$ 0.0155

Busy period of Repairman (Inspection time) $\left(\mathrm{B}_{0}^{\mathrm{I}}\right)=0.0225$

Busy period of Repairman (Repair time) $\left(\mathrm{B}_{0}^{\mathrm{R}}\right)=0.0046$

Busy period of Repairman (Replacement time) $\left(\mathrm{B}_{0}^{\mathrm{Rp}}\right)=$ 0.0092

Power degradation per unit time $=0.00064$

Using above numerical values, various graphs are drawn for $\operatorname{MTSF}\left(\mathrm{T}_{0}\right)$, Availability with full/ reduced capacity $\left(\mathrm{R}_{0} / \mathrm{AR}_{0}\right)$ and profit $\left(\mathrm{P}_{0}\right)$ of the system for different values of rates of minor faults, major faults as well as rate of power degradation $\left(\lambda_{1}, \lambda_{2}, \lambda_{3}\right)$, different inspection rates $\left(\eta_{1}, \eta_{2}\right)$, different costs $\left(\mathrm{C}_{0}, \mathrm{C}_{6}\right)$ etc.

Following has been interpreted and concluded from the graphs so formed:

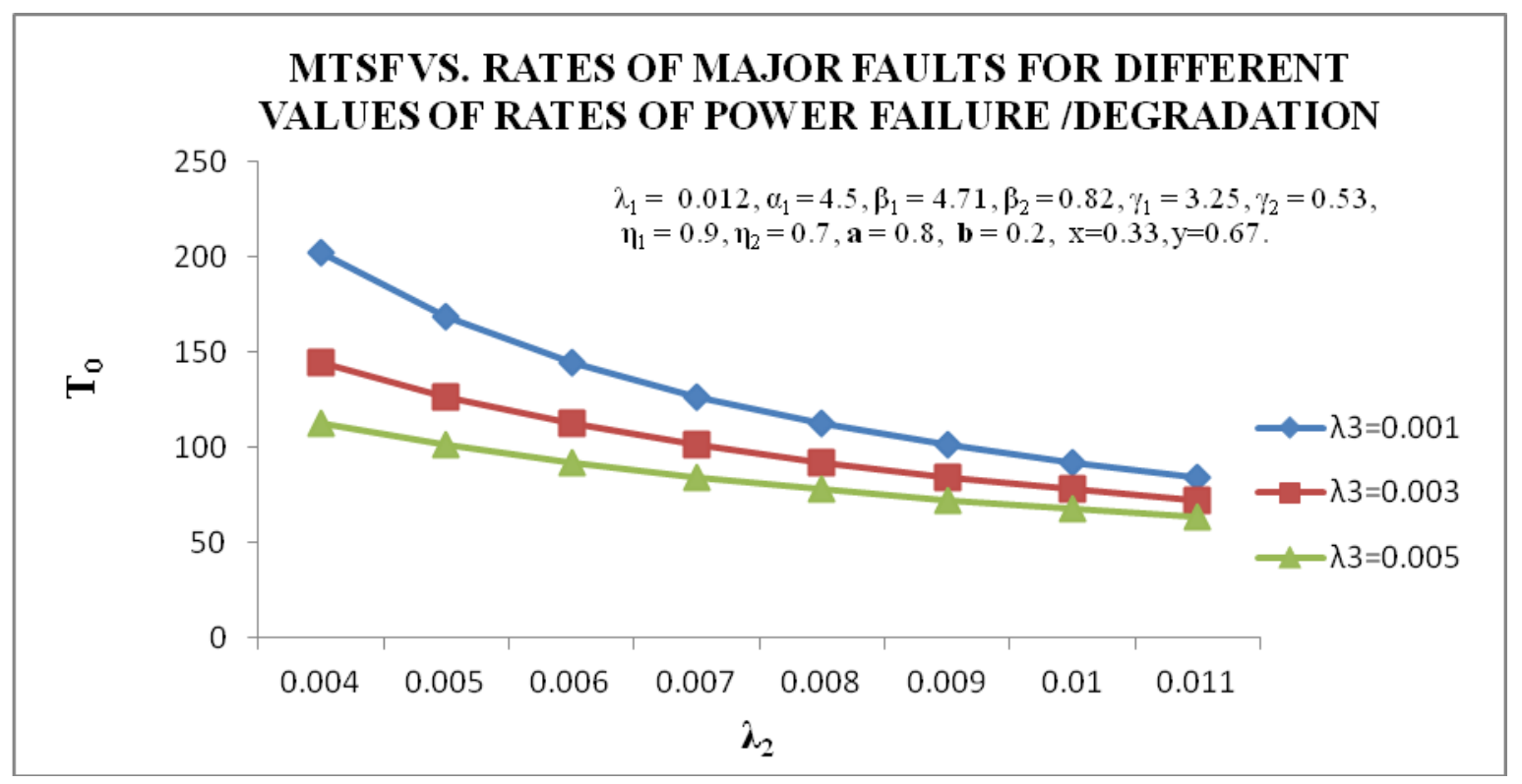

Figure.2.

Fig.2 gives the graph between MTSF $\left(\mathrm{T}_{0}\right)$ and the rate of major faults $\left(\lambda_{2}\right)$ for different values of rate of power degradation $\left(\lambda_{3}\right)$. The graph shows that the MTSF decreases with the increase in the values of rate of major faults and it has lower value for higher values of rate of power degradation. 


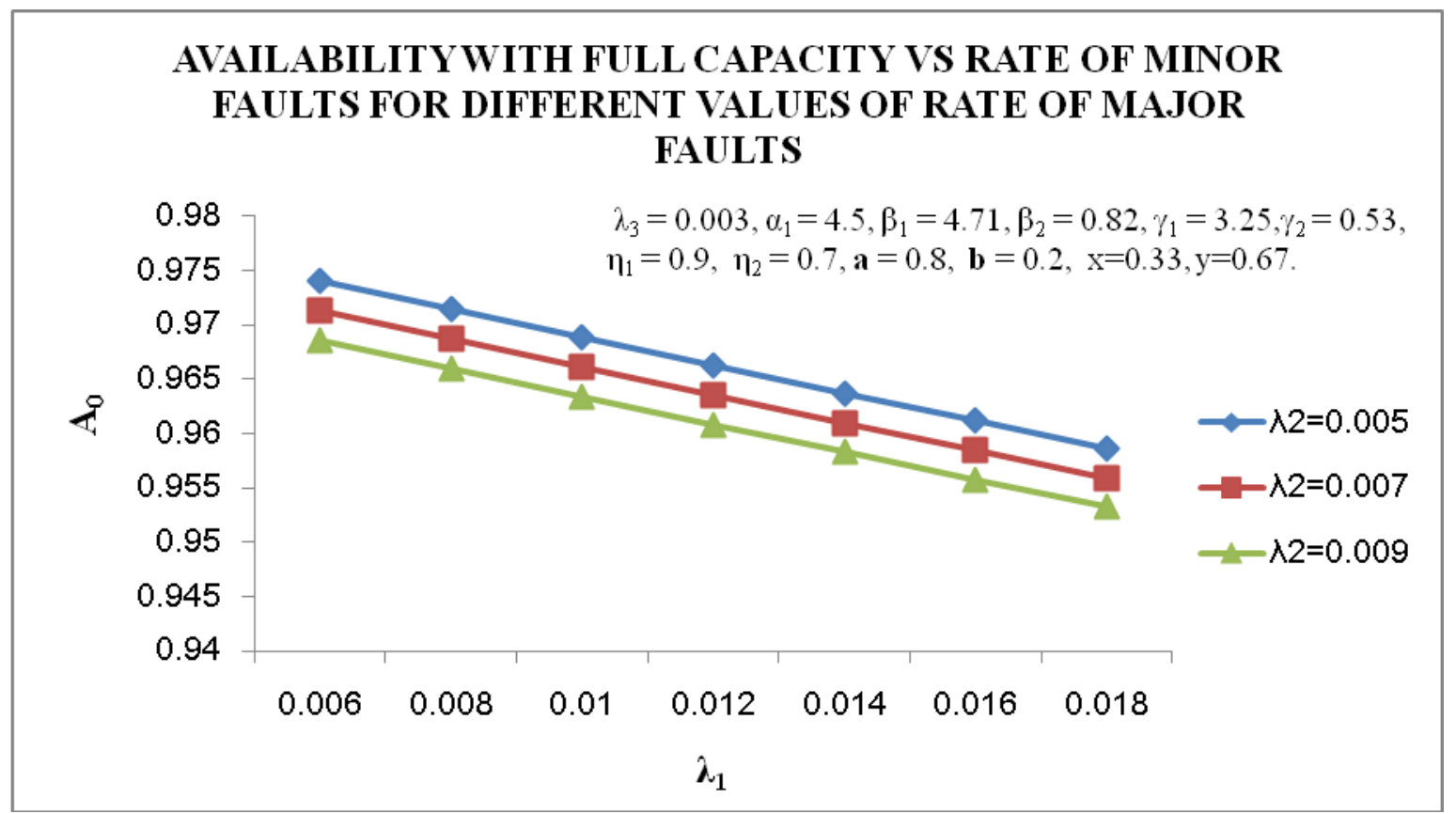

Figure.3.

Fig. 3 is the graph between availability with full capacity $\left(\mathrm{A}_{0}\right)$ and the rate of minor faults $\left(\lambda_{1}\right)$ for different values of rate of major faults $\left(\lambda_{2}\right)$. It reveals that availability with full capacity decreases with the increase in the value of rate of minor faults and it has lower values for higher values of rate of major faults.

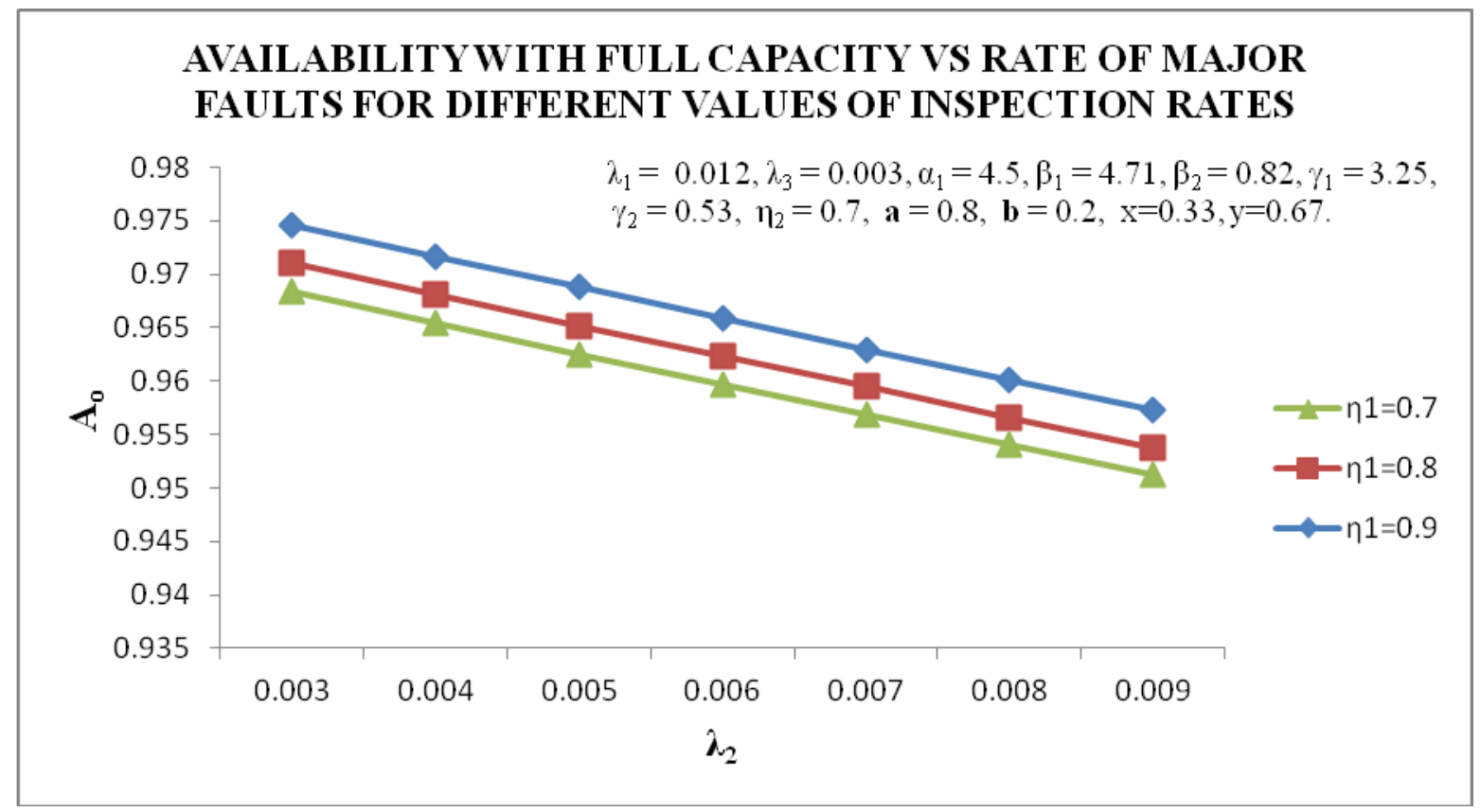

Figure.4. 
Fig.4 presents the graph between availability with full capacity $\left(\mathrm{A}_{0}\right)$ and rate of major faults $\left(\lambda_{2}\right)$ for different values of inspection rates $\left(\eta_{1}\right)$. It can be concluded from the graph that the availability with full capacity decreases with the increase in the value of rate of major faults and it has lower value for lower inspection rate.

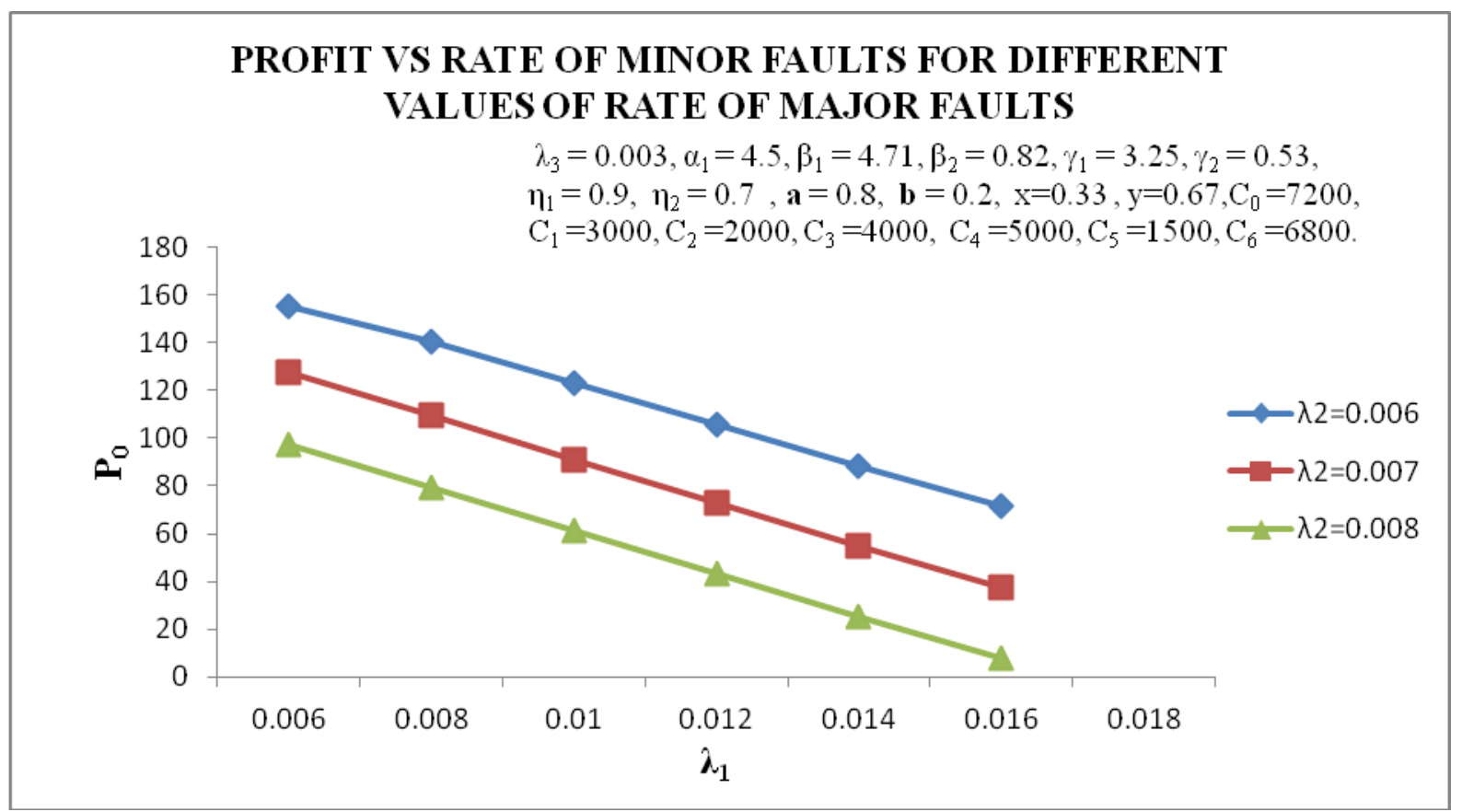

Figure.5.

In graph at Fig.5 relation has been shown between profit $\left(\mathrm{P}_{0}\right)$ and rate of minor faults $\left(\lambda_{1}\right)$ for different values of rate of major faults $\left(\lambda_{2}\right)$. It reveals that the profit decreases with the increase in the value of rate of minor faults and also it is shown that it has lower values for higher values of rate of major faults.

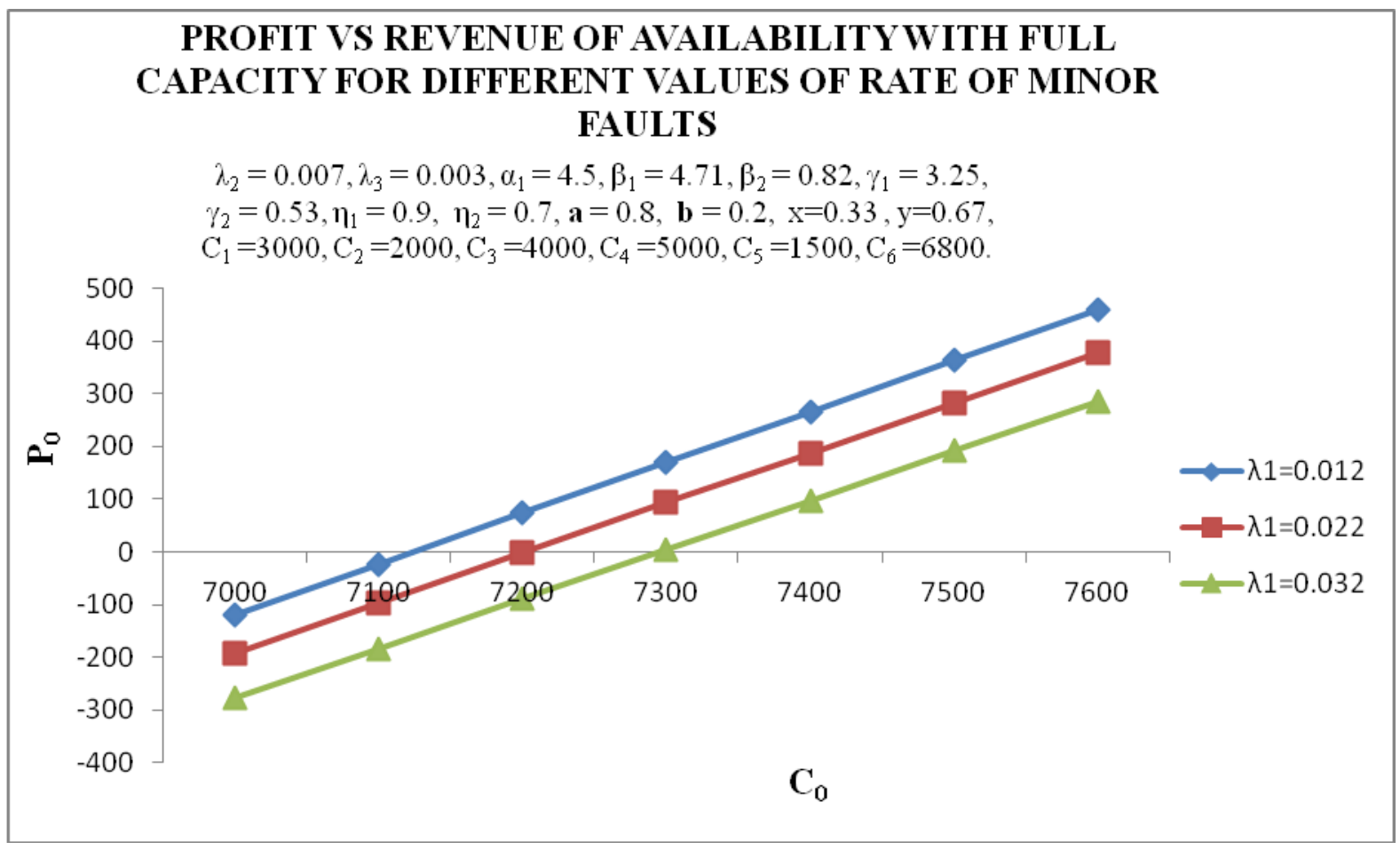


Figure.6.

Graph at Fig.6 is between profit $\left(\mathrm{P}_{0}\right)$ and the revenue of availability with full capacity $\left(\mathrm{C}_{0}\right)$ for different values of rate of minor faults $\left(\lambda_{1}\right)$.

From the graph, we have concluded as follows:

1. The profit increases with the increase in the revenue of availability with full capacity and it has lower values for higher values of rate of minor faults.

2. For $\lambda_{1}=0.012$, the profit is negative or zero or positive according as $\mathrm{C}_{0}$ is less than or equal or greater than Rs.7123.8. Thus, the machine will give profit for this when $\mathrm{C}_{0}$ is greater than Rs.7123.8.

3. For $\lambda_{1}=0.022$, the profit is negative or zero or positive according as $\mathrm{C}_{0}$ is less than or equal or greater than Rs.7202.3. Thus, the machine will give profit for this when $\mathrm{C}_{0}$ is greater than Rs.7202.3.

4. For $\lambda_{1}=0.032$, the profit is negative or zero or positive according as $\mathrm{C}_{0}$ is less than or equal or greater than Rs.7295.4. Thus, the machine will give profit for this when $\mathrm{C}_{0}$ is greater than Rs.7295.4.

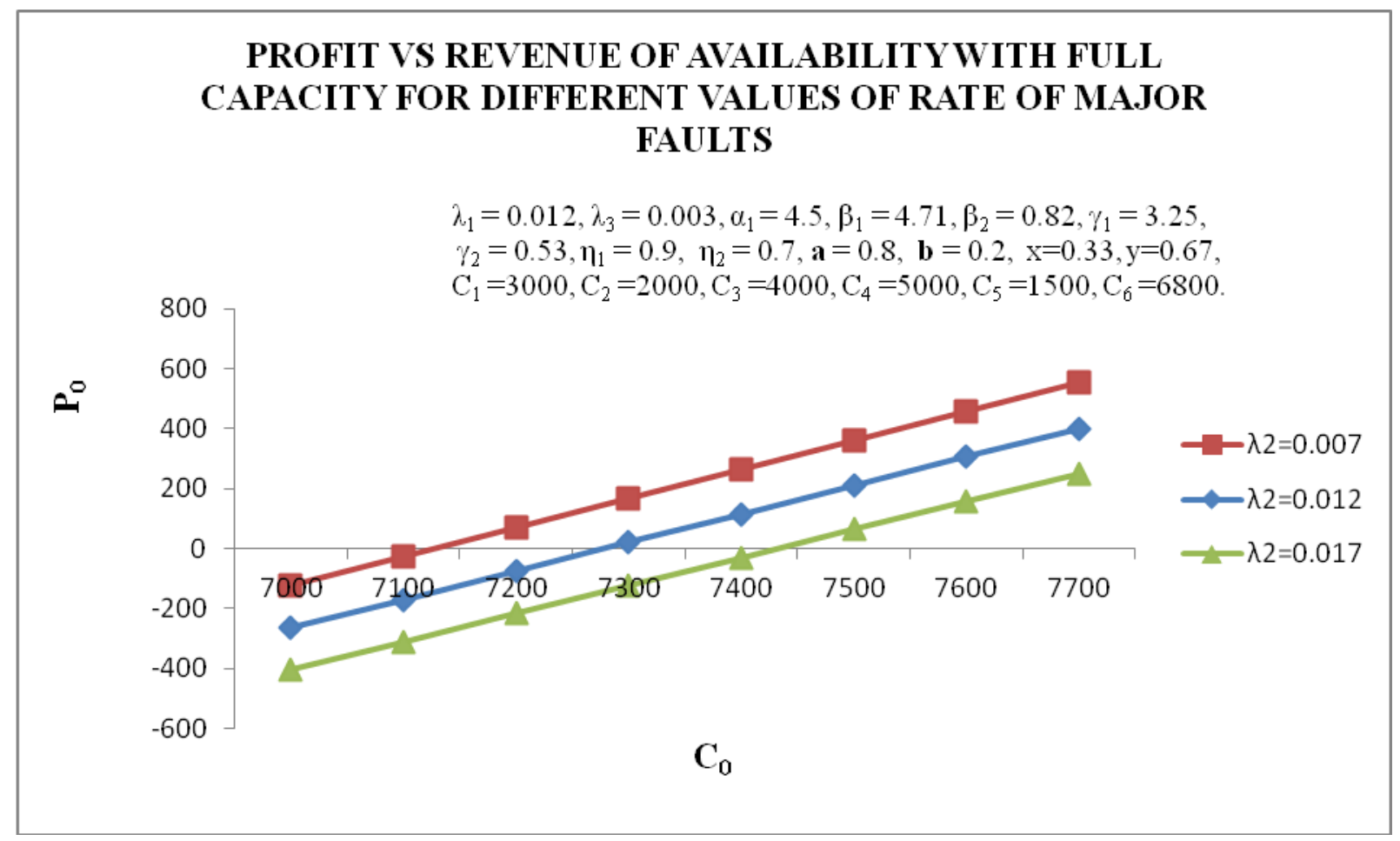

Figure.7.

Fig. 7 shows the graph between profit $\left(\mathrm{P}_{0}\right)$ and the revenue of availability with full capacity $\left(\mathrm{C}_{0}\right)$ for different values of rate of major faults $\left(\lambda_{2}\right)$.

We have concluded from the graph as follows: i) The profit increases with the increase in the revenue of availability with full capacity and it has lower values for higher values of rate of major faults. 
ii) For $\lambda_{2}=0.007$, the profit is negative or zero or positive according as $\mathrm{C}_{0}$ is less than or equal or greater than Rs.7123.8. Thus, the machine will give profit for this when $\mathrm{C}_{0}$ is greater than Rs.7123.8.

iii) For $\lambda_{1}=0.012$, the profit is negative or zero or positive according as $\mathrm{C}_{0}$ is less than or equal or greater than Rs.7277.6. Thus, the machine will give profit for this when $\mathrm{C}_{0}$ is greater than Rs.7277.6.

iv) For $\lambda_{1}=0.017$, the profit is negative or zero or positive according as $\mathrm{C}_{0}$ is less than or equal or greater than Rs.7431. Thus, the machine will give profit for this when $\mathrm{C}_{0}$ is greater than Rs.7431.

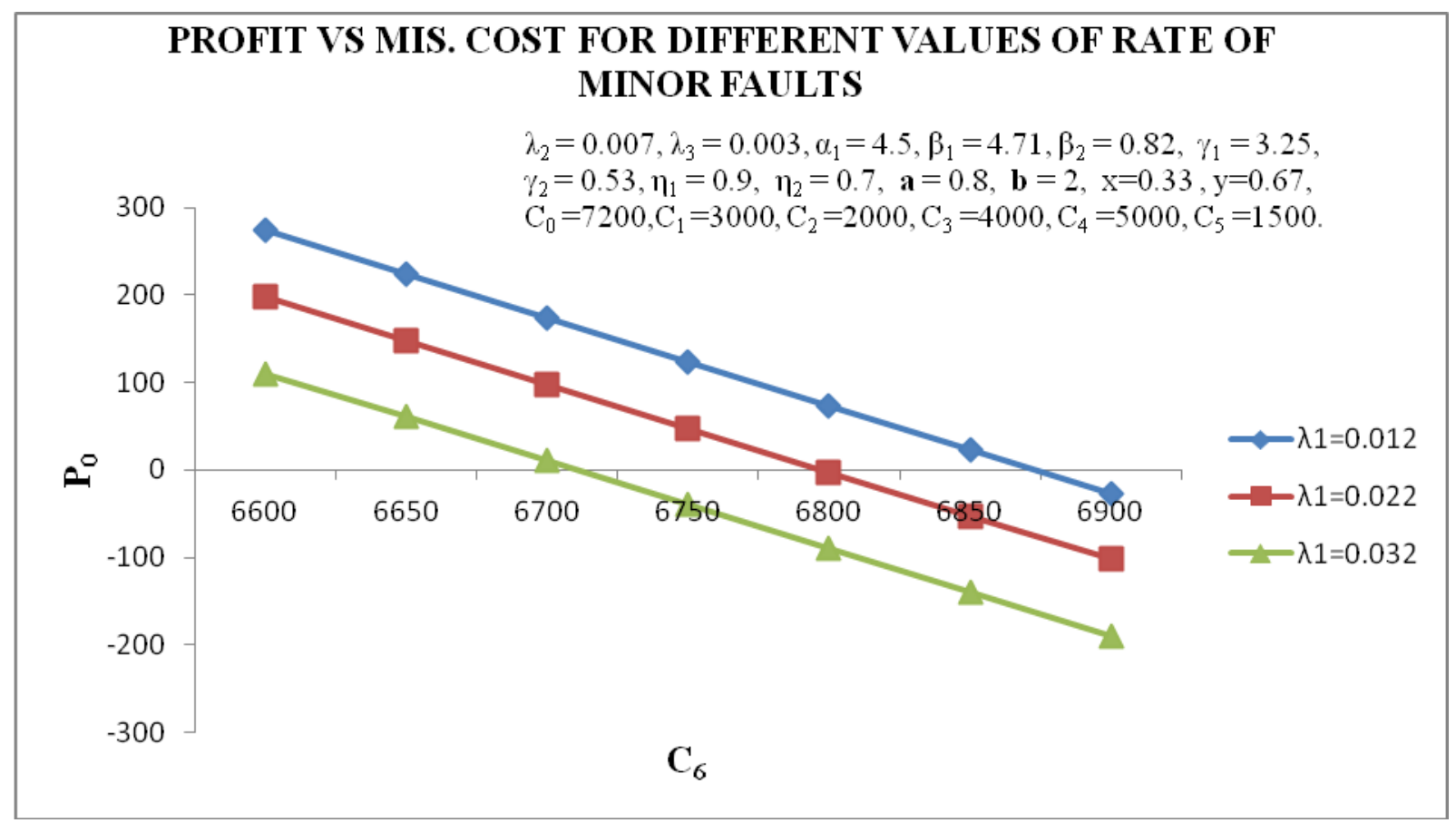

Figure.8.

Fig. 8 is the graph between profit $\left(\mathrm{P}_{0}\right)$ and miscellaneous cost $\left(\mathrm{C}_{6}\right)$ for different values of rate of minor faults $\left(\lambda_{1}\right)$.

The conclusions of the graph are as follows:

I. The profit decreases with the increase in the miscellaneous cost and it has lower values for higher values of rate of minor faults.

II. For $\lambda_{1}=0.012$, the profit is negative or zero or positive according as $\mathrm{C}_{6}$ is greater than or equal or less than Rs.6873.4.
Thus, the machine will give profit for this when $\mathrm{C}_{6}$ is less than Rs.6873.4.

III. For $\lambda_{1}=0.022$, the profit is negative or zero or positive according as $\mathrm{C}_{6}$ is greater than or equal or less than Rs.6797.7. Thus, the machine will give profit for this when $\mathrm{C}_{6}$ is less than Rs.6797.7.

IV. For $\lambda_{1}=0.032$, the profit is negative or zero or positive according as $\mathrm{C}_{6}$ is greater than or equal or less than Rs.6710.3. Thus, the machine will give profit for this when $\mathrm{C}_{0}$ is less than Rs.6710.3. 


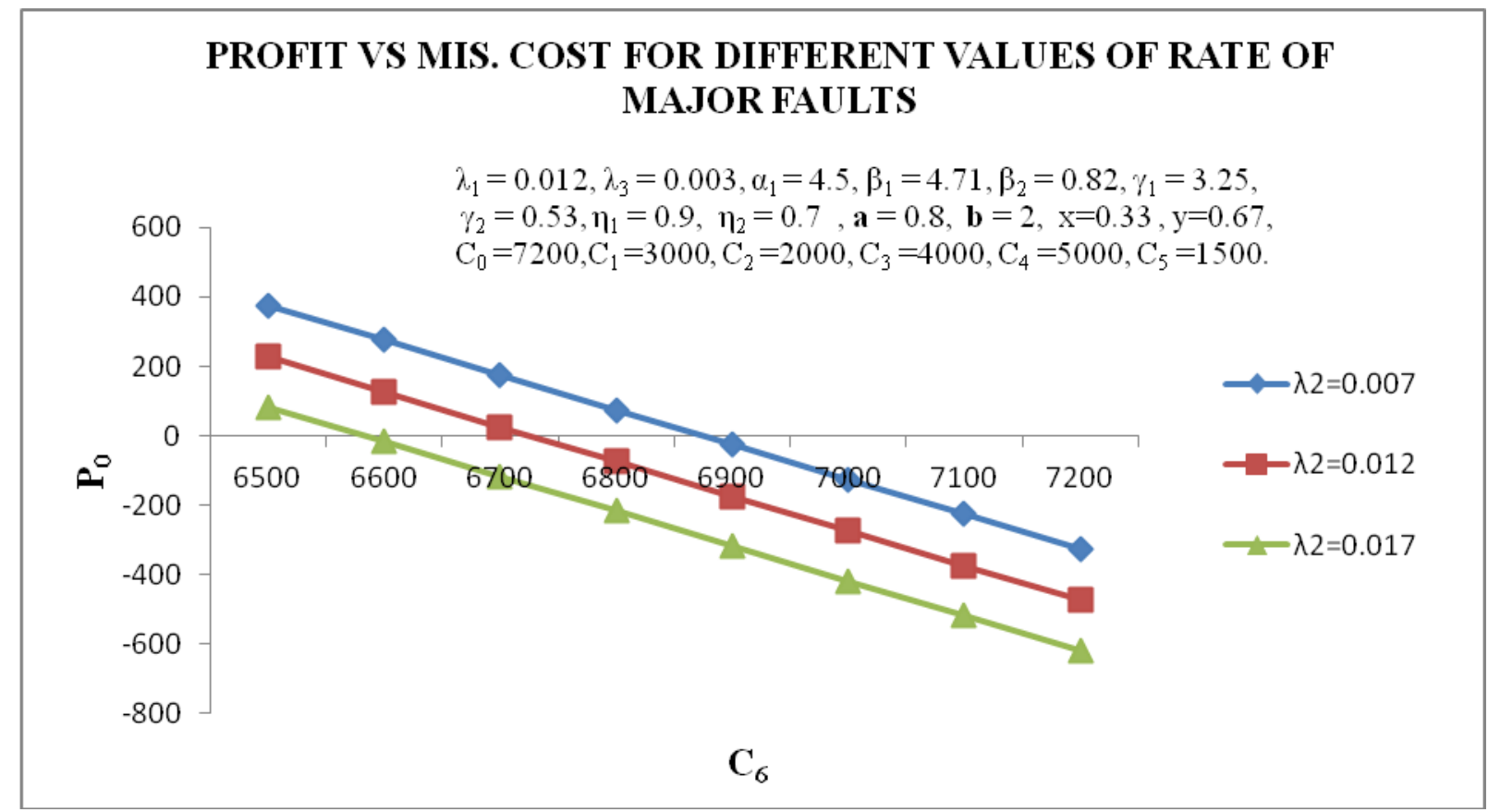

Figure.9.

Fig.9 gives the graph between profit $\left(\mathrm{P}_{0}\right)$ and the miscellaneous cost $\left(\mathrm{C}_{6}\right)$ for different values of rate of major faults $\left(\lambda_{2}\right)$.

Following are conclusions of the graph:

a. The profit decreases with the increase in the miscellaneous cost and it has lower values for higher values of rate of major faults.

b. For $\lambda_{2}=0.007$, the profit is negative or zero or positive according as $\mathrm{C}_{6}$ is greater than or equal or less than Rs.6873.4. Thus, the machine will give profit for this when $\mathrm{C}_{6}$ is less than Rs.6873.4.

c. For $\lambda_{2}=0.012$, the profit is negative or zero or positive according as $\mathrm{C}_{6}$ is greater than or equal or less than Rs.6726.2. Thus, the machine will give profit for this when $\mathrm{C}_{6}$ is less than Rs.6726.2. d. For $\lambda_{2}=0.032$, the profit is negative or zero or positive according as $\mathrm{C}_{6}$ is greater than or equal or less than Rs.6583.1. Thus, the machine will give profit for this when $\mathrm{C}_{6}$ is less than Rs.6583.1.

\section{CONCLUSION:}

From analysis of the graphs above, we conclude that mean time to system failure, availability and the profit per unit time of the paper machine decreases with the increase in the values of the rate of minor as well as major faults. Further, we obtained cut off points of profit for different values of rates of minor/major faults, for revenue of availability/costs etc. We derived that, for particular value of rate of minor/major fault what should be the greater value of revenue of availability or lower value of miscellaneous costs to get positive profit. On the basis of these values, various suggestions can be given to the management team of the Paper Mill to make the paper machine profitable. 
International Journal of Science and Engineering Applications

Volume 9 - Issue 07, 91 - 102, 2020, ISSN:- 2319 - 7560

\section{REFERENCES:}

[1] Branson, M.H. and Shah, B. (1971): "Reliability Analysis of System Comprises of Units with Arbitrary Repair Time Distributions", IEEE Transactions on Reliability, Vol. 20 pp. $217-223$.

[2] Nakagawa, T. (1976): “On a Replacement Problem of a Cumulative Damage Model”, J. Oper. Res. Quart., 27, pp. 895-900.

[3] Balagurusamy, E. (1984): "Reliability Engineering”, Tata McGraw Hill Publishing Co. Ltd., India.

[4] Goel, L.R., Sharma, G.C. and Gupta, R. (1986): "Reliability Analysis of a System with Preventive Maintenance and Two Types of Repair", Microelectron. Reliab., Vol. 26, pp. 429-433.

[5] D.Kumar, J.Singh, and P.C.Pandey (1989): "Availability of a Washing System in the Paper Industry”, Microelectronics Reliability, vol.29, no.5, pp.775-778.

[6] P.Gupta, A.K.Lal, R.K.Sharma, and J.Singh (2005): "Numerical Analysis of Reliability and Availability of the Serial Processes in Butter-oil Processing Plant," International Journal of Quality and Reliability Management, vol.22, no.3, pp.303-316.

[7] R.Kumar and P Bhatia (2011): "Reliability and Cost Analysis of a One Unit Centrifuge System with Single Repairman and Inspection", Pure and Applied Mathematics Sciences, Vol.LXXIV, no.12, pp.113-121.
[8] Malik, S.C.and Deswal, Savita (2012): "Stochastic Analysis of a Repairable System of Non-Identical Units with Priority for Operation and Repair Subject to Weather Conditions", International Journal of Computer Applications,vol.49(14),pp.33-41.

[9] Kumar, R. and Bhatia, P. (2013): "Performance and Profit Evaluations of a Stochastic Model on Centrifuge System working in Thermal Power Plant Considering Neglected Faults." International Journal of Scientific and Statistical Computing, Malasia, ISSN:2180-1339,Vol.4(1), pp. 10-18, 2013.

[10] S.P.Sharma and Y. Vishwakarma (2014): "Application of Markov Process in Performance Analysis of Feeding System of Sugar Industry", Journal of Industrial Mathematics, vol.2014, Article ID 593176.

[11] Renu, and Bhatia, P.(2017): "Reliability Analysis for Removing Shortcoming Using Stochastic Process and Apply for Maintenance in Industry", Special Issue of International Journal of Engineering Science and Technology, pp.62-66.

[12] Rajaprasad (2018): "Investigation of Reliability, Maintainability and Availability of a Paper Machine in an Integrated Pulp and Paper Mill.” Journal of Engineering, Science and Technology, Vol. 10, No. 3, 2018, pp. 43-56. 